\title{
Clinical implication of ZEB-1 and E-cadherin expression in hepatocellular carcinoma $(\mathrm{HCC})$
}

\author{
Motoyuki Hashiguchi ${ }^{1}$, Shinichi Ueno ${ }^{1,2^{*}}$, Masahiko Sakoda', Satoshi lino ${ }^{1}$, Kiyokazu Hiwatashi ${ }^{1}$, Koji Minami ${ }^{1}$, \\ Kei Ando ${ }^{1}$, Yuko Mataki ${ }^{1}$, Kosei Maemura ${ }^{1}$, Hiroyuki Shinchi ${ }^{1}$, Sumiya Ishigami ${ }^{1}$ and Shoji Natsugoe ${ }^{1}$
}

\begin{abstract}
Background: While recent research has shown that expression of ZEB-1 in a variety of tumors has a crucial impact on patient survival, there is little information regarding ZEB-1 expression in hepatocellular carcinoma (HCC). This study investigated the co-expression of ZEB-1 and E-cadherin in HCC by immunohistochemistry and evaluated its association with clinical factors, including patient prognosis.
\end{abstract}

Methods: A total of 108 patients with primary HCC treated by curative hepatectomy were enrolled. ZEB-1 expression was immunohistochemically categorized as positive if at least $1 \%$ cancer cells exhibited nuclear staining. E-cadherin expression was divided into preserved and reduced expression groups and correlations between ZEB-1 and E-cadherin expression and clinical factors were then evaluated.

Results: With respect to ZEB-1 expression, 23 patients were classified into the positive group and 85 into the negative group. Reduced E-cadherin expression was seen in 44 patients and preserved expression in the remaining 64 patients. ZEB-1 positivity was significantly associated with reduced expression of E-cadherin $(p=0.027)$. Moreover, significant associations were found between ZEB-1 expression and venous invasion and TNM stage. ZEB-1 positivity was associated with poorer prognosis $(p=0.025)$. Reduced E-cadherin expression was significantly associated with intrahepatic metastasis and poorer prognosis $(p=0.047)$. In particular, patients with both ZEB-1 positivity and reduced E-cadherin expression had a poorer prognosis $(p=0.005)$. Regardless of E-cadherin status, ZEB-1 was not a significant prognostic factor by multivariate analysis. There was no statistical difference in overall survival when E-cadherin expression was reduced in the ZEB-1 positive group ( $p=0.24)$.

Conclusions: Positive ZEB-1 expression and loss of E-cadherin expression are correlated with poor prognosis in HCC patients and malignancy of ZEB-1 positive tumors involves EMT.

Keywords: Hepatocellular carcinoma, Hepatic resection, ZEB-1, E-cadherin, EMT

\section{Background}

Hepatocellular carcinoma (HCC) is a major health problem worldwide, with an estimated incidence ranging between 500,000 and 1,000,000 new cases annually. It is the fifth most common cancer in the world, and the third most common cause of cancer-related death. The disease is highly lethal because of its aggressive metastasis and an advanced stage at the time of diagnosis [1].

\footnotetext{
* Correspondence: ueno1@m.kufm.kagoshima-u.ac.jp

'Department of Digestive Surgery, Breast and Thyroid Surgery, Kagoshima University Graduate School of Medicine and Dental Sciences, Kagoshima, Japan

${ }^{2}$ Department of Clinical Oncology, Course of Advanced Therapeutics, Kagoshima University Graduate School of Medicine and Dental Sciences, Kagoshima, Japan
}

\section{Biomed Central}

(c) 2013 Hashiguchi et al.; licensee BioMed Central Ltd. This is an open access article distributed under the terms of the Creative Commons Attribution License (http://creativecommons.org/licenses/by/2.0), which permits unrestricted use, distribution, and reproduction in any medium, provided the original work is properly cited.
Recent developments in surgical and medical therapies have significantly improved the outcome of patients with both operable and advanced HCC [2,3]. Although there is recent evidence that these patients benefit from new molecular targeted therapies, systemic chemotherapy is not as effective as expected in patients with advanced HCC [4].

It has recently become clear that epithelial-mesenchymal transition (EMT) plays an important role in cancer progression, metastasis and chemoresistance, most likely involving a common molecular mechanism. However, the involvement of EMT varies greatly among cancer types, and much remains to be elucidated [5,6]. A hallmark of EMT is down-regulation of the cell adhesion molecule 
E-cadherin, a transmembrane protein essential for the establishment of stable adherent junctions, and upregulation of mesenchymal molecules including vimentin, fibronectin and/or $\mathrm{N}$-cadherin. It has been reported that repression of E-cadherin is associated with dedifferentiation, infiltrative growth and high incidence of lymph node metastasis in several cancers [7-9]. E-cadherin is repressed by multiple mechanisms, including gene mutation, promoter hypermethylation, or promoter repression by transcription repressors during tumor progression. A variety of transcription factors including the zinc finger Snail homologues (Snail1, Snail2/Slug, and Snail3) and several basic helix-loop-helix factors such as Twist, ZEB1, and ZEB2, all interact with the E-box element within the proximal region of the E-cadherin promoter [5,8,10,11]. ZEB-1, like other EMT-inducing transcription factors such as Twist, Snail, Slug and SIP, binds DNA using similar E-box sequence motifs, thereby effecting repression of E-cadherin [12]. Aberrant expression of ZEB1 in endometrial cancers, colorectal carcinomas and prostate cancer has been associated with aggressive disease, poor differentiation, the development of metastases and poor clinical prognosis [6,8-10].

In the oncogenic pathway, transforming growth factor$\beta$ (TGF- $\beta$ ) signaling is also critical for EMT induction [13]. The relationship between TGF- $\beta$ and cancer promotion has been examined from various viewpoints [13-16], and recently, it has been reported that TGF- $\beta$ stimulates EMT by two mechanisms [14]. The first, namely canonical signaling, involves a heterocomplex of activated $\operatorname{Smad} 2 / 3$ and $\operatorname{smad} 4$. The second, termed noncanonical signaling, involves induction of EMT gene expression by ZEB-1 and other transcription factors such as Snail, Twist or and Stat3, culminating in prolonged induction of EMT. We previously observed elevated expression of Smad4 in $35.5 \%$ of patients in HCC, and that this status was correlated with a poor prognosis [17].

The aim of this study was to investigate the association between the expression status of ZEB-1 and E-cadherin in $\mathrm{HCC}$ using immunohistochemistry, and to evaluate the clinical impact of the expression status of these proteins.

\section{Methods}

\section{Patients and tumor samples}

108 patients with primary single nodular HCC (85 men and 23 women, with a mean age of 65.3 years) were treated by hepatic partial resection between January 1996 and December 2002. Surgical specimens from these patients were used in this study. As shown in Table 1, of these 108 patients, 18 patients were positive for the hepatitis B surface antigen, 76 were positive for anti-hepatitis $C$ virus antibodies, 1 was positive for both
Table 1 Characteristics of patients

\begin{tabular}{lll}
\hline Gender & & \\
\hline Male & 85 & $(78.7 \%)$ \\
female & 23 & $(21.3 \%)$ \\
Mean age & 65.3 years & \\
Hepatitis virus type & & \\
B & 18 & $(16.7 \%)$ \\
C & 76 & $(70.4 \%)$ \\
B +C & 1 & $(0.9 \%)$ \\
None & 13 & $(12 \%)$ \\
Mean tumor size & $44.3 \mathrm{~mm}$ & \\
Histological grade (Differentiation) & & $(16.7 \%)$ \\
Well & 18 & $(72.2 \%)$ \\
Moderate & 78 & $(11.1 \%)$ \\
Poor & 12 & \\
Total & 108 & \\
\hline
\end{tabular}

viruses and 13 were negative for both viruses. Mean tumor diameter was $44.3 \mathrm{~mm}$ (range $10-150 \mathrm{~mm}$ ). The histological grade of each tumor and the tumor staging were determined by the General Rules for the Clinical and Pathological Study of Primary Liver Cancer (The Liver Cancer Study Group of Japan, 2009, 5th edition). 18 tumors $(16.7 \%)$ showed well-differentiated HCC, 78 (72.2\%) tumors were moderately differentiated, and 12 (11.1\%) tumors were poorly differentiated. Follow-up data after surgery were obtained from all patients, with a median follow-up period of 48.4 months. Before tissue acquisition, each patient provided written informed consent to participate in the study, which was approved by the ethics committees of Kagoshima University School of Medicine.

\section{Antibodies}

Goat anti-human polyclonal antibody to ZEB-1 was purchased from SANTA CRUZ BIOTECHNOLOGY, Inc. (Santa Cruz, CA, USA). Mouse anti-human monoclonal antibody to E-cadherin was purchased from DAKO JAPAN (Tokyo, Japan).

\section{Immunohistochemistry}

Avidin-biotinylated peroxidase complex (ABC) immunohistochemistry was performed as follows. 4-mm thick sections were cut from paraffin blocks of HCC. After deparaffinization and rehydration, heat-induced antigen retrieval by autoclave pretreatment $\left(120^{\circ} \mathrm{C}\right.$ for $\left.10 \mathrm{~min}\right)$ in citrate buffer solution ( $\mathrm{pH}$ 6.0) was performed. Endogenous peroxidase activity was blocked by immersing the slides in absolute methanol solution containing 3\% hydrogen peroxide for $10 \mathrm{~min}$. Endogenous biotin activity was blocked using an avidin/biotin blocking kit 
purchased from NICHIREI, (Tokyo, Japan). Sections were incubated in avidin solution for 15 minutes followed a by brief rinse in PBS, after which sections were incubated in biotin solution for 15 minutes (all at room temperature). Sections were then treated with $1 \%$ bovine serum albumin for $30 \mathrm{~min}$ to block nonspecific reactions, after which they were incubated with ZEB-1 antibody (1:100 dilution) or E-cadherin antibody (1:100 dilution) for one hour at room temperature. Following incubation, specimens were visualized with an $A B C$ detection kit (Vector laboratory, Burlingame, $\mathrm{CA}$ ) and a diaminobenzidine (DAB) substrate system, according to the instructions provided by the manufacturer. Slides were counterstained with hematoxylin before mounting. All reactions were performed using appropriate positive and negative controls, and no significant staining was observed in the negative control sections.

\section{Evaluation of immunohistochemistry}

In order to evaluate the results by immunohistochemical staining, ten fields of each specimen were selected. The expression in 1,000 tumor cells (100 cells/field) was evaluated with high-power $(\times 400)$ microscopy. Two investigators (M.H. and S.U.) assessed the slides without knowledge of the clinicopathological features and were blinded to each other's evaluation. They were in agreement on all the slides examined.

\section{Statistical analysis}

Statistical analysis of group differences was performed using the $x^{2}$ test or Student's t-test. The Kaplan-Meier method and subsequent evaluation by log-rank test were used for overall survival analysis. The prognostic factors were examined by univariate and multivariate analyses (proportional hazards regression model). A P-value of less than 0.05 was considered to be statistically significant.

\section{Results}

\section{Expression of ZEB-1 and E-cadherin in HCC}

ZEB-1 was detected in the cellular nuclei of HCC cells (Figure 1a). All noncancerous liver cells were ZEB-1 negative (Figure 1c). ZEB-1 expression was classified into four groups: absent ( $\mathrm{n}=85$; Figure $1 \mathrm{e}), 1 \sim 5 \%$ of all cancer cells $(\mathrm{n}=12), 6 \sim 10 \%(\mathrm{n}=7)$ and $>10 \%(\mathrm{n}=4)$. Since the frequency of ZEB-1 expression was low, ZEB-1 expression was categorized as positive if at least $1 \%$ of cancer cells exhibited nuclear staining $(n=23 ; 21.3 \%)$ or as negative if very few or no cancer cells were stained ( $\mathrm{n}=85 ; 78.7 \%$ ).

E-cadherin was detected in the cellular membranes of HCC and in the normal glands of the liver (Figure 1d, f). E-cadherin expression was compared between malignant cells and noncancerous liver cells located away from the tumor. Tumor cells with a staining intensity equal to or greater than that of noncancerous liver cells were considered to be preserved expression ( $\mathrm{n}=64,59.3 \%$; Figure 1f)), whereas those with a weaker staining intensity than noncancerous liver cells or with no expression at all, were considered to be reduced expression $(n=44$, 40.7\%; Figure $1 \mathrm{~b})$.

\section{Correlation between ZEB-1 and E-cadherin expression and clinicopathological factors}

Table 2 shows the correlation between immunohistochemical expression and clinicopathological factors. Positive expression of ZEB-1 in 23 HCCs (21.3\%) was significantly associated with vascular invasion $(\mathrm{p}=0.016)$ and advanced tumor TNM stage $(p=0.023)$. Furthermore, there was a trend towards an increased frequency of intrahepatic metastasis in the ZEB-1 positive group $(\mathrm{p}=0.078)$. Reduced $\mathrm{E}$-cadherin expression in 44 HCCs $(40.7 \%)$ was significantly associated with intrahepatic metastasis $(\mathrm{p}<0.001)$ and advanced tumor stage $(\mathrm{p}=0.05)$.

Finally, reduced E-cadherin expression was significantly associated with positive ZEB-1 expression $(\mathrm{p}=0.027)$.

\section{Prognostic impact of ZEB-1 and E-cadherin expression}

Figure 2a \& b shows overall survival curves after surgery according to ZEB-1 and E-cadherin expression (Figure $2 \mathrm{a}, \mathrm{b}$ ). The 5-year survival rates of patients with positive and negative expression of ZEB-1 were 38.1 and $63.4 \%$, respectively $(p=0.025)$. Similarly, the 5 -year survival rate was significantly better in the E-cadherin preserved group than in the reduced E-cadherin group (5year 66.0 vs. $45.5 \%, \mathrm{p}=0.048$ ).

Overall survival was evaluated according to the various combinations of the expression patterns of ZEB-1 and E-cadherin. When comparing between patients with ZEB-1 positive and reduced E-cadherin expression and patients with other expression pattern combinations (Figure 2c), the former group showed a significantly poorer prognosis ( 5 -year 29.5 vs. $62.2 \%, \mathrm{p}=0.005$ ).

There was no statistical difference in overall survival when E-cadherin expression was reduced in the ZEB-1 positive group $(\mathrm{p}=0.24)$ (Figure $2 \mathrm{~d})$.

\section{Univariate and multivariate analyses}

Factors relating to the patients' prognosis were evaluated by univariate and multivariate analyses (Table 3 ). Univariate analysis showed that intrahepatic metastasis $(\mathrm{p}=$ 0.0007), vascular invasion ( $\mathrm{p}=0.047)$ and ZEB-1 expression $(\mathrm{p}=0.037)$ were significantly related to postoperative survival. There was a strong trend towards association of reduced E-cadherin expression with poor prognosis $(\mathrm{p}=0.053)$. In the multivariate analysis, only 

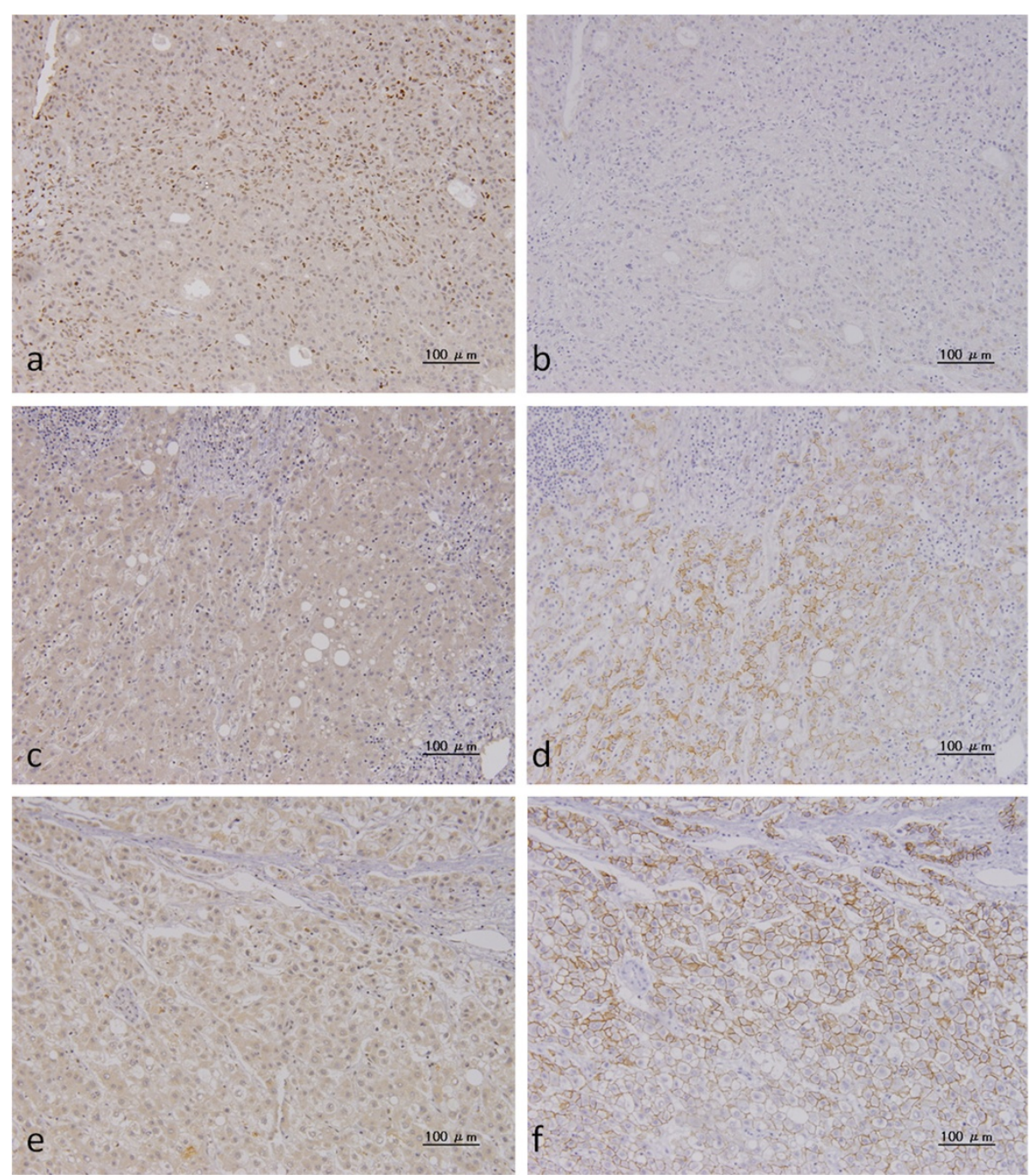

Figure 1 Immunohistochemical analysis of ZEB-1 and E-cadherin expression. ZEB-1 antibody was purchased from SANTA CRUZ BIOTECHNOLOGY, Inc. and E-cadherin antibody was purchased from DAKO JAPAN. Images from representative cases are shown: case 1 (a - d) and case 2 (e. f). Case 1 was classified as $>10 \%$ ZEB-1 positive. a. Positive expression of ZEB-1 in cellular nuclei in HCC. $\mathbf{b}$. Reduced expression of E-cadherin in HCC cells. c. ZEB-1 expression is undetectable in noncancerous liver cells. d. E-cadherin expression was observed in the cell membrane in noncancerous liver cells. Case 2 was classified as ZEB-1 negative. e. ZEB-1 was not detected in the cell nuclei in HCC cells. f. E-cadherin expression was preserved in the cell membrane in HCC cells.

intrahepatic metastasis $(\mathrm{p}=0.0086)$ was an independent prognostic factor.

\section{Discussion}

ZEB-1 (also known as dEF1, Nil-2-a, Tcf8, Bzp, Areb6, Meb1, Zfhx1a and Zfhep) has been identified as a nuclear factor that specifically binds to and represses the avian lens-specific d1-crystallin enhancer [18]. ZEB-1 is a DNA binding transcriptional repressor that interacts in a ligand-dependent fashion with receptor-activated Smad transcription factors involved in mediating TGF- $\beta$ signaling [19]. Recent research has shown that expression of ZEB-1 has a crucial impact on patient survival [20]. Positive expression of ZEB-1 in endometrial cancers, colorectal carcinomas, and prostate cancer has been associated with aggressive disease, poor differentiation, development of metastases, and poor clinical prognosis [21-24]. In contrast, there is little information regarding the clinical implications of ZEB-1 expression in HCC, nor the relationship between ZEB-1 and E-cadherin expression in HCC.

In this study, we immunohistochemically investigated ZEB-1 expression in HCC and evaluated its association with clinical factors, including patient prognosis. For the purposes of this study, ZEB-1 positive expression was defined as $>1 \%$ ZEB-1 positive HCC cells, although it should be noted that this is not an established method. A similar ZEB-1 positive percentage $(14 / 110,12 \%)$ in 
Table 2 Clinicopathological Variables and ZEB1 and E-cadherin expression in HCC

\begin{tabular}{|c|c|c|c|c|c|c|c|}
\hline \multirow[b]{2}{*}{ Variable } & \multirow[b]{2}{*}{$\begin{array}{l}\text { Total no. } \\
(n=108)\end{array}$} & \multicolumn{3}{|l|}{ ZEB1 } & \multicolumn{3}{|l|}{ E-cadherin } \\
\hline & & $\begin{array}{l}\text { positive } \\
(n=23)\end{array}$ & $\begin{array}{l}\text { negative } \\
(\mathrm{n}=85)\end{array}$ & $p$-value & $\begin{array}{l}\text { preserved } \\
(n=64)\end{array}$ & $\begin{array}{l}\text { reduced } \\
(n=44)\end{array}$ & $p$-value \\
\hline \multicolumn{8}{|l|}{ Gender } \\
\hline Male & 85 & 18 & 67 & 0.996 & 47 & 38 & 0.107 \\
\hline Female & 23 & 5 & 18 & & 17 & 6 & \\
\hline \multicolumn{8}{|c|}{ Tumor size (mm) } \\
\hline$\geqq 4.5 \mathrm{~cm}$ & 33 & 10 & 27 & 0.227 & 21 & 16 & 0.702 \\
\hline$<4.5 \mathrm{~cm}$ & 75 & 13 & 58 & & 43 & 28 & \\
\hline \multicolumn{8}{|c|}{ Vascular invasion } \\
\hline Present & 38 & 13 & 25 & 0.016 & 21 & 17 & 0.533 \\
\hline Absent & 70 & 10 & 60 & & 43 & 27 & \\
\hline \multicolumn{8}{|c|}{ Infiltration into capsule (Fc-inf) } \\
\hline Present & 84 & 18 & 66 & 0.95 & 51 & 33 & 0.565 \\
\hline Absent & 24 & 5 & 19 & & 13 & 11 & \\
\hline \multicolumn{8}{|c|}{ Intrahepatic metastasis } \\
\hline Present & 27 & 9 & 18 & 0.078 & 13 & 33 & $<0.001$ \\
\hline Absent & 81 & 14 & 67 & & 51 & 11 & \\
\hline \multicolumn{8}{|c|}{ Gross classification $^{*}$} \\
\hline Localized & 69 & 13 & 56 & 0.095 & 43 & 26 & 0.389 \\
\hline Invasive & 29 & 10 & 19 & & 21 & 18 & \\
\hline \multicolumn{8}{|l|}{ Differentiation $^{*}$} \\
\hline Well & 18 & 3 & 15 & 0.5 & 9 & 9 & 0.717 \\
\hline Moderate & 76 & 15 & 61 & & 46 & 30 & \\
\hline Poor & 12 & 4 & 8 & & 7 & 5 & \\
\hline \multicolumn{8}{|c|}{ PIVKA II level $(\mathrm{mAU} / \mathrm{ml})(n=91)$} \\
\hline Normal $(\leqq 40)$ & 23 & 5 & 18 & 0.906 & 16 & 7 & 0.36 \\
\hline High $(>40)$ & 68 & 14 & 54 & & 40 & 28 & \\
\hline \multicolumn{8}{|c|}{ AFP level $(\mathrm{ng} / \mathrm{ml})(\mathrm{n}=95)$} \\
\hline Normal $(\leqq 20)$ & 48 & 10 & 38 & 0.837 & 29 & 19 & 0.732 \\
\hline High (>20) & 47 & 9 & 38 & & 30 & 17 & \\
\hline \multicolumn{8}{|c|}{ Pathological TMN Stage ${ }^{*}$} \\
\hline$I+\|+|I|$ & 88 & 15 & 73 & 0.023 & 56 & 32 & 0.05 \\
\hline IV & 20 & 8 & 12 & & 8 & 12 & \\
\hline \multicolumn{8}{|c|}{ Immunohistochemical staining } \\
\hline ZEB-1 & & & & & & & 0.027 \\
\hline Positive & 23 & & 9 & & 14 & & \\
\hline negative & 80 & & & & 55 & 30 & \\
\hline
\end{tabular}

"The histological grade of each tumor and the tumor staging were determined by the General Rules for the Clinical and Pathological Study of Primary Liver Cancer (The Liver Cancer Study Group of Japan, 2009, 5th edition).

HCC has been previously reported in an immunohistochemical analysis [25]. We showed that positive expression of ZEB-1 was significantly associated with vascular invasion $(\mathrm{p}=0.016)$, tumor TNM stage $(\mathrm{p}=0.024)$, and prognosis $(p=0.025)$. Using western blot, Zhou et al. showed that elevated expression of ZEB-1 occurred in
65.4\% (72/110) of HCC tissues and was a significant prognostic factor for poor overall and disease-free survival rates [26]. A caveat of Western blot is that it may not completely exclude the influence of differences in expression in different regions of the tumor, nor the contribution of contaminating fibroblasts. In order to 


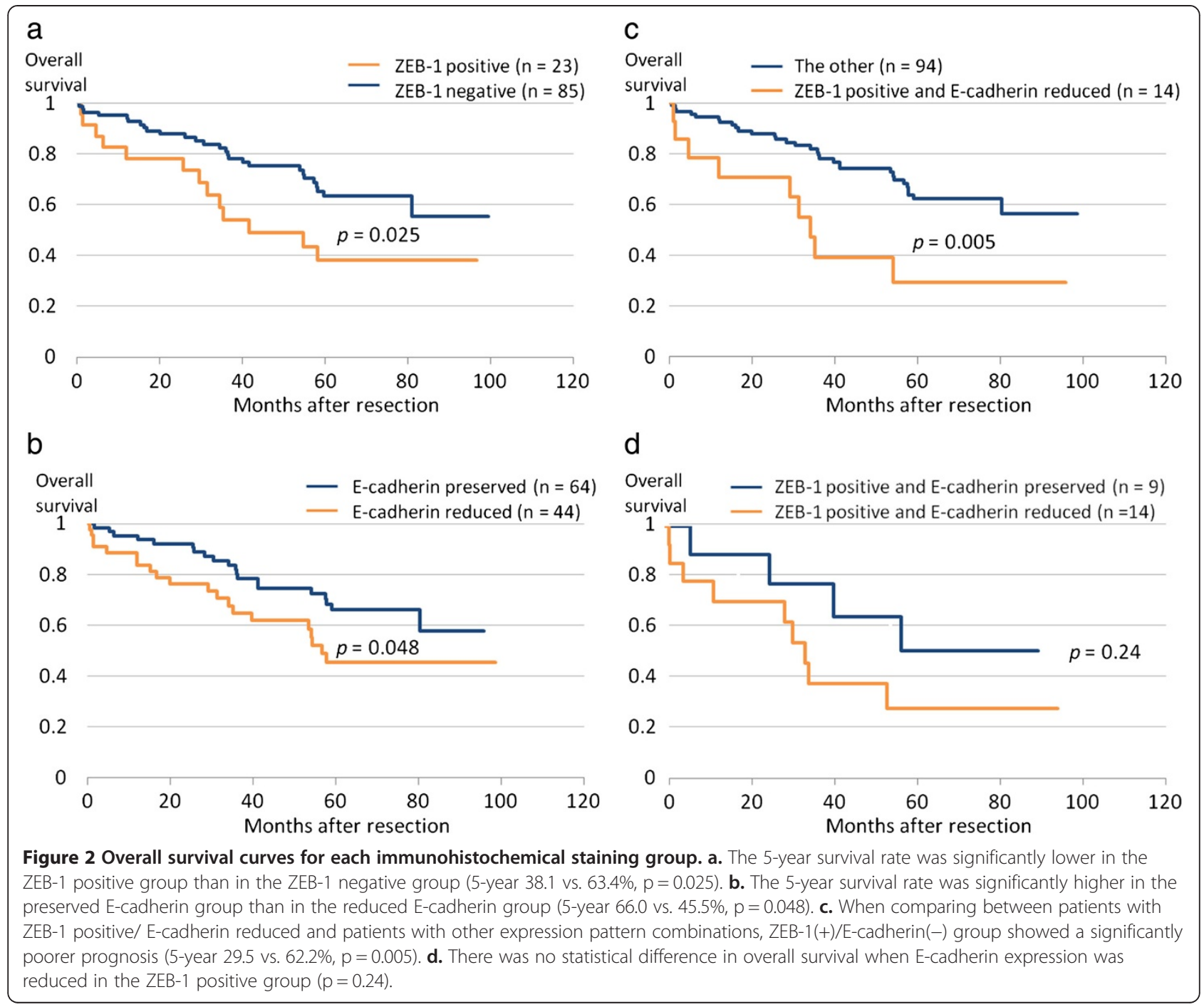

better understand its effect on tumor function, ZEB-1 expression in HCC cells should be studied in isolation. Accordingly, in the present study we examined ZEB-1 expression using immunohistochemical analysis. In this report, while the frequency of ZEB1 expression in the nuclei of HCC cells was lower than that in previous reports [26], patient prognosis was significantly poorer when ZEB-1 positive cells were present in HCC tissues. Moreover, increased ZEB-1 expression cells was associated with markedly worse prognosis (data not shown).
We suggest that immunohistochemical evaluation of ZEB-1 expression in tumor nuclei may have clinical prognostic impact.

Reduced E-cadherin expression has been observed in $\mathrm{HCC}$, in particular in poorly-differentiated cancers $[27,28]$. We also showed that reduced expression of Ecadherin was significantly associated with increased intrahepatic metastasis $(\mathrm{p}<0.001)$ and poorer prognosis $(p=0.048)$. When we analyzed the relationship between ZEB-1 and E-cadherin expression, the combination of

Table 3 Univariate and Multivariate analysis of overall survival

\begin{tabular}{|c|c|c|c|c|c|c|}
\hline \multirow[b]{2}{*}{ Variables } & \multicolumn{3}{|c|}{ Univariate } & \multicolumn{3}{|c|}{ Multivariate } \\
\hline & $\mathrm{HR}$ & $95 \% \mathrm{Cl}$ & p-value & $\mathrm{HR}$ & $96 \% \mathrm{Cl}$ & $p$-value \\
\hline Intrahepatic metastasis & 1.80 & $1.30-2.47$ & 0.0007 & 1.67 & $1.14-2.41$ & 0.0086 \\
\hline Vascular invasion & 0.72 & $1.00-1.88$ & 0.047 & 1.08 & $0.74-1.55$ & 0.696 \\
\hline Positive ZEB1 & 1.45 & $1.02-2.00$ & 0.037 & 1.20 & $0.83-1.71$ & 0.320 \\
\hline Reducing E-cadherin & 1.36 & $1.00-1.86$ & 0.053 & 1.31 & $0.95-1.81$ & 0.101 \\
\hline
\end{tabular}


positive ZEB-1 expression and reduced E-cadherin expression was associated with the worst prognosis among the various combinations of ZEB-1 and E-cadherin expression. Again using western blot, Zhou et al. also observed a significant correlation between lower Ecadherin protein expression and elevated ZEB-1 expression in HCC specimens [26]. High expression of ZEB-1 may further enhance its inhibition of the expression of the E-cadherin gene, causing a decrease in E-cadherin levels and an increase in migration and invasiveness in cancer cells [21-24,29,30]. Acquisition of an invasive phenotype through EMT, which enables cancer cells to break away from the primary tumor and invade surrounding tissues, may strongly promote the spread of cancer cells into the portal venous circulation.

During the EMT process, epithelial cancer cells acquire fibroblast-like properties and malignant potential through both canonical and non-canonical TGF- $\beta$ signaling pathways $[13,14]$. Activation of canonical Smad2/ 3 signaling results in nuclear translocation of these factors with Smad4 and subsequent regulation of gene expression through their numerous interactions with additional transcriptional activators and repressors. We have previously shown that strong expression of Smad4 occurs in $35.5 \%$ of patients in HCC, and is associated with a poor prognosis $(\mathrm{p}=0.04)$ [17]. In this study however, we found that a combination of ZEB1 and Ecadherin expression was a more powerful statistical tool than Smad4 in predicting clinical outcome. Alternatively, activation of factors in noncanonical TGF- $\beta$ signaling, such as MAP kinases, small GTPases, PI3K/AKT, and NF- $\kappa B$, also couples TGF- $\beta$ to regulation of EMT expression programs. Finally, activation of transcription factors belonging to the Snail family (e.g., Snail, Twist, or ZEB-1), or of Stat3, induces genes associated with EMT, which ultimately promotes progression of EMT. In this study, we correlated positive expression of ZEB-1 and reduced expression of $\mathrm{E}$-cadherin with poorer prognosis in HCC. We speculate that EMT is active in ZEB-1 positive tumors, and that both canonical and noncanonical signaling systems are influential in HCC.

\section{Conclusions}

In conclusion, it is likely that positive ZEB-1 expression and reduced E-cadherin expression are correlated with the progression of HCC through their influence on the progression of EMT. Accordingly, inhibition of the expression or function of EMT-inducing transcription factors in malignant carcinoma is anticipated to lead to new therapeutic strategies.

\section{Competing interests}

The authors declare that they have no competing interests.

\section{Authors' contributions}

$\mathrm{MH}$ and SU initiated the study, participated in its design and coordination, carried out the study, performed the statistical analysis. MH, SU and SN drafted the manuscript. MS, SI, KH, KM, KA, YM, KM, HS and SI provided data, contributed to data interpretation. All authors read and approved the final manuscript.

\section{Acknowledgement}

This work was supported in part by Grants-in-Aid from the Ministry of Education, Science, Sports and Culture of Japan (No. 23591992 to S. U.)

Received: 15 February 2013 Accepted: 26 November 2013

Published: 5 December 2013

\section{References}

1. Lau WY, Lai EC: Hepatocellular carcinoma: current management and recent advances. Hepatobiliary Pancreat Dis Int 2008, 7(3):237-257.

2. Ueno S, Kubo F, Sakoda M, Hiwatashi K, Tateno T, Mataki Y, Maemura K, Shinchi H, Natsugoe S, Aikou T: Efficacy of anatomic resection vs nonanatomic resection for small nodular hepatocellular carcinoma based on gross classification. J Hepatobiliary Pancreat Surg 2008, 15(5):493-500

3. Cucchetti A, Cescon M, Trevisani F, Pinna AD: Current concepts in hepatic resection for hepatocellular carcinoma in cirrhotic patients. World J Gastroenterol 2012, 18(44):6398-6408.

4. Rahbari NN, Mehrabi A, Mollberg NM, Muller SA, Koch M, Buchler MW, Weitz J: Hepatocellular carcinoma: current management and perspectives for the future. Ann Surg 2011, 253(3):453-469.

5. Kalluri $R$, Weinberg RA: The basics of epithelial-mesenchymal transition. J Clin Invest 2009, 119(6):1420-1428.

6. Kang $Y$, Massague J: Epithelial-mesenchymal transitions: twist in development and metastasis. Cell 2004, 118(3):277-279.

7. Karayiannakis AJ, Syrigos KN, Chatzigianni E, Papanikolaou S, Alexiou D, Kalahanis N, Rosenberg T, Bastounis E: Aberrant E-cadherin expression associated with loss of differentiation and advanced stage in human pancreatic cancer. Anticancer Res 1998, 18(6A):4177-4180.

8. Winter JM, Ting AH, Vilardell F, Gallmeier E, Baylin SB, Hruban RH, Kern SE, lacobuzio-Donahue CA: Absence of E-cadherin expression distinguishes noncohesive from cohesive pancreatic cancer. Clin Cancer Res 2008, 14(2):412-418.

9. Joo YE, Rew JS, Park CS, Kim SJ: Expression of E-cadherin, alpha- and betacatenins in patients with pancreatic adenocarcinoma. Pancreatology 2002, 2(2):129-137.

10. Peinado H, Olmeda D, Cano A: Snail, Zeb and bHLH factors in tumour progression: an alliance against the epithelial phenotype? Nat Rev Cancer 2007, 7(6):415-428

11. Zeisberg $M$, Neilson EG: Biomarkers for epithelial-mesenchymal transitions. J Clin Invest 2009, 119(6):1429-1437.

12. Eger A, Aigner $\mathrm{K}$, Sonderegger $\mathrm{S}$, Dampier B, Oehler S, Schreiber M, Berx G, Cano A, Beug H, Foisner R: DeltaEF1 is a transcriptional repressor of $\mathrm{E}$-cadherin and regulates epithelial plasticity in breast cancer cells. Oncogene 2005, 24(14):2375-2385.

13. Wu Y, Zhou BP: New insights of epithelial-mesenchymal transition in cancer metastasis. Sheng Wu Hua Xue Yu Sheng Wu Wu Li Xue Bao (Shanghai) 2008, 40(7):643-650.

14. Wendt MK, Allington TM, Schiemann WP: Mechanisms of the epithelialmesenchymal transition by TGF-beta. Future Oncol 2009, 5(8):1145-1168.

15. Kaimori A, Potter J, Kaimori JY, Wang C, Mezey E, Koteish A: Transforming growth factor-beta1 induces an epithelial-to-mesenchymal transition state in mouse hepatocytes in vitro. J Biol Chem 2007, 282(30):22089-22101

16. Nitta T, Kim JS, Mohuczy D, Behrns KE: Murine cirrhosis induces hepatocyte epithelial mesenchymal transition and alterations in survival signaling pathways. Hepatology 2008, 48(3):909-919.

17. Hiwatashi K, Ueno S, Sakoda M, Kubo F, Tateno T, Kurahara H, Mataki Y, Maemura K, Ishigami S, Shinchi H, et al: Strong Smad4 expression correlates with poor prognosis after surgery in patients with hepatocellular carcinoma. Ann Surg Oncol 2009, 16(11):3176-3182.

18. Funahashi J, Sekido R, Murai K, Kamachi Y, Kondoh H: Delta-crystallin enhancer binding protein delta EF1 is a zinc finger-homeodomain 
protein implicated in postgastrulation embryogenesis. Development 1993, 119(2):433-446.

19. Verschueren K, Remacle JE, Collart C, Kraft H, Baker BS, Tylzanowski P, Nelles L, Wuytens G, Su MT, Bodmer R, et al: SIP1, a novel zinc finger/homeodomain repressor, interacts with Smad proteins and binds to 5 -CACCT sequences in candidate target genes. J Biol Chem 1999, 274(29):20489-20498.

20. Vandewalle C, Van Roy F, Berx G: The role of the ZEB family of transcription factors in development and disease. Cell Mol Life Sci 2009. 66(5):773-787.

21. Graham TR, Zhau HE, Odero-Marah VA, Osunkoya AO, Kimbro KS, Tighiouart M, Liu T, Simons JW, O'Regan RM: Insulin-like growth factor---dependent up-regulation of ZEB1 drives epithelial-to-mesenchymal transition in human prostate cancer cells. Cancer Res 2008, 68(7):2479-2488.

22. Singh M, Spoelstra NS, Jean A, Howe E, Torkko KC, Clark HR, Darling DS, Shroyer KR, Horwitz KB, Broaddus RR, et al: ZEB1 expression in type I vs type II endometrial cancers: a marker of aggressive disease. Mod Pathol 2008, 21(7):912-923.

23. Spaderna S, Schmalhofer O, Hlubek F, Berx G, Eger A, Merkel S, Jung A, Kirchner T, Brabletz T: A transient, EMT-linked loss of basement membranes indicates metastasis and poor survival in colorectal cancer. Gastroenterology 2006, 131(3):830-840.

24. Spoelstra NS, Manning NG, Higashi Y, Darling D, Singh M, Shroyer KR, Broaddus RR, Horwitz KB, Richer JK: The transcription factor ZEB1 is aberrantly expressed in aggressive uterine cancers. Cancer Res 2006 66(7):3893-3902.

25. Liu TA, Jan YJ, Ko BS, Liang SM, Chen SC, Wang J, Hsu C, Wu YM, Liou JY: 14-3-3epsilon overexpression contributes to epithelial-mesenchymal transition of hepatocellular carcinoma. PLoS One 2013, 8(3):e57968.

26. Zhou YM, Cao L, Li B, Zhang RX, Sui CJ, Yin ZF, Yang JM: Clinicopathological significance of ZEB1 protein in patients with hepatocellular carcinoma. Ann Surg Oncol 2012, 19(5):1700-1706.

27. Ihara A, Koizumi H, Hashizume R, Uchikoshi T: Expression of epithelial cadherin and alpha- and beta-catenins in nontumoral livers and hepatocellular carcinomas. Hepatology 1996, 23(6):1441-1447.

28. Wei Y, Van Nhieu JT, Prigent S, Srivatanakul P, Tiollais P, Buendia MA: Altered expression of E-cadherin in hepatocellular carcinoma: correlations with genetic alterations, beta-catenin expression, and clinical features. Hepatology 2002, 36(3):692-701.

29. Huang MT, Wei PL, Liu JJ, Liu DZ, Huey-Chun H, An J, Wu CC, Wu CH, Ho YS, Yang YY, et al: Knockdown of thrombomodulin enhances HCC cell migration through increase of ZEB1 and decrease of E-cadherin gene expression. Ann Surg Oncol 2010, 17(12):3379-3385.

30. Jia B, Liu H, Kong Q, Li B: Overexpression of ZEB1 associated with metastasis and invasion in patients with gastric carcinoma. Mol Cell 2012, 366(1-2):223-229.

doi:10.1186/1471-2407-13-572

Cite this article as: Hashiguchi et al: Clinical implication of ZEB-1 and E-cadherin expression in hepatocellular carcinoma (HCC). BMC Cancer 2013 13:572.

\section{Submit your next manuscript to BioMed Central and take full advantage of:}

- Convenient online submission

- Thorough peer review

- No space constraints or color figure charges

- Immediate publication on acceptance

- Inclusion in PubMed, CAS, Scopus and Google Scholar

- Research which is freely available for redistribution 